\title{
Factors Influencing Willingness to Donate to Marine Endangered Species Recovery in the Galapagos National Park, Ecuador
}

\author{
Susana A. Cárdenas ${ }^{1,2 *}$ and Daniel K. Lew ${ }^{3,4}$ \\ ${ }^{1}$ Ecology Graduate Group, Department of Environmental Science and Policy, University of California, Davis, Davis, CA, USA, \\ ${ }^{2}$ Department of Agricultural and Resource Economics, University of California, Davis, Davis, CA, USA, ${ }^{3}$ Resource Ecology \\ and Fisheries Management Division, Alaska Fisheries Science Center, National Marine Fisheries Service, Seattle, WA, USA, \\ ${ }^{4}$ Department of Environmental Science and Policy, University of California, Davis, Davis, CA, USA
}

\section{OPEN ACCESS}

Edited by:

Lyne Morissette,

$M$ - Expertise Marine, Canada

Reviewed by:

Pablo Pita

University of Santiago de Compostela,

Spain

E. Christien Michael Parsons, George Mason University, USA

*Correspondence:

Susana A. Cárdenas sacardenas@ucdavis.edu

Specialty section:

This article was submitted to Marine Affairs and Policy, a section of the journal Frontiers in Marine Science

Received: 18 December 2015

Accepted: 15 April 2016

Published: 02 May 2016

Citation:

Cárdenas SA and Lew DK (2016) Factors Influencing Willingness to

Donate to Marine Endangered Species Recovery in the Galapagos National Park, Ecuador.

Front. Mar. Sci. 3:60.

doi: 10.3389/fmars.2016.00060
Willingness to donate (WTD) money for the conservation of endangered species may depend on numerous factors. In this paper, we analyze data from a survey given to tourists visiting Ecuador's Galapagos National Park and Marine Reserve to investigate determinants of their WTD toward the conservation of two marine endangered species-the scalloped hammerhead shark (Sphyrna lewini) and the green sea turtle (Chelonia mydas). Specifically, we use regression analysis to analyze the influence of attitudes and beliefs toward species conservation, levels of concern for specific species, recreational motivations, and past donation patterns on WTD, while also controlling for individual characteristics such as age, gender, place of residence, and other demographics. Additionally, we evaluate the sensitivity of WTD to the species being protected by conservation efforts. Our results demonstrate that specific concern about the species, beliefs about donating to the protection program, and past donation behavior significantly influence the intention to donate money toward the recovery of the two marine endangered species. The likelihood of donating to green sea turtle conservation efforts is marginally higher than for hammerhead sharks, possibly due to its more charismatic nature. In contrast, visitors who are more willing to donate for shark conservation appear to be those with a strong desire to see them in the wild. The results provide useful information on the heterogeneity of tourist preferences toward donating to species conservation efforts, which has broad implications for resource agencies seeking ways to fund conservation actions.

Keywords: marine endangered species, donation behavior, conservation attitudes, attitude-behavior modeling, eco-tourism, Galapagos National Park, scalloped hammerhead shark, green sea turtle

\section{INTRODUCTION}

A primary management tool proposed to reduce impacts of human behavior on the ocean is the marine protected area (MPA). To date, more than 11,300 MPAs encompass $2.12 \%$ of the world's oceans, with $0.94 \%$ in strongly protected no-take marine reserves (Marine Conservation Institute, 2015). The benefits of MPAs include the protection and rebuilding of commercial fish populations 
(Gell and Roberts, 2003), the protection of vulnerable habitats and species (Rodrigues et al., 2004), and the provision of opportunities for tourism, recreation, and education (Ham and Weiler, 2012).

For endangered migratory marine megafauna (such as sea turtles, sharks, and whales), protection is required beyond the existing MPAs. Thus, marine conservationists have been advocating to increase the global coverage of MPAs and to create networks of MPAs (Balmford et al., 2005; IUCN, 2008).

Marine tourism is an emerging recreational activity around the world with the potential to contribute to conservation. Specifically, marine wildlife tourism, defined as any tourist activity with the primary purpose of watching, studying, or enjoying non-consumptive activities with marine wildlife (including diving and snorkeling), has been growing in recent decades (Masters, 1998; Stoeckl et al., 2010). Zeppel (2008) provides a summary of studies that show that marine mammals, sea turtles, seabirds, and sharks are key tourism attractions. Stoeckl et al. (2005) also emphasize the positive economic impact of wildlife tourism related to well-known species on coastal destinations. Some documented examples include watching whales, sea turtles, whale sharks, and dolphins, mainly in Australia and New Zealand (Davis et al., 2000; Hoyt, 2001; Wilson and Tisdell, 2001; Orams, 2003). Other studies have also found that recreational experiences with iconic marine species have contributed to pro-environmental attitudes and post-experience intention to engage in their conservation (Mayes et al., 2004; Zeppel and Muloin, 2008) ${ }^{1}$. For instance, visitor surveys after marine wildlife tours in Australia have shown that visitors are willing to help protect marine endangered species through personal conservation actions (e.g., report poaching or educate others) and through monetary donations for conservation (Tisdell and Wilson, 2001; Mayes et al., 2004).

Despite concerns about the impacts of increased marine tourism in some places (Hall, 2001; Dikou, 2011; Gladstone et al., 2013), the benefits from environmentally-friendly and wellmanaged tourism initiatives can promote and assist in coastal and marine conservation efforts. Thus, the growth of marine tourism represents a potential win-win for marine conservation and natural resource agencies. That is, the high cost associated with marine protection (Balmford et al., 2003) and limited funding sources (Gravestock et al., 2008) stand out as the main constraints to the creation of new MPAs and protection of existing MPAs. Tourists potentially could provide the resources needed to expand marine protection if resource agencies could design funding mechanisms that actively involve them. For this to happen, however, a better understanding of tourists' motivations, intentions, and behavior toward the support for marine endangered species is needed to design effective funding and conservation initiatives.

Over the past decades, researchers have examined social factors that influence people's interest in conserving a variety of environmental goods, including endangered species, and have

\footnotetext{
${ }^{1}$ However, few studies have examined whether visitors continue to support or engage in conservation efforts after these types of trips (see Ballantyne et al., 2011 for an exception).
}

advocated taking into account the social context for successful conservation strategies (DeCaro and Stokes, 2008; Choi and Fielding, 2013). Part of this research has involved testing conceptual frameworks that explain the way individuals link their values, beliefs, attitudes, and contextual factors to proenvironmental intentions and behaviors (Ajzen, 1991; Fulton et al., 1996; Stern, 2000).

When analyzing pro-environmental behavior, it is important to distinguish behavioral intentions from actual behavior. The Theory of Planned Behavior (Ajzen, 1991), or TPB, emphasizes the relationship between intention and behavior. Under this theoretical framework, the individual's intentions capture the motivational factors that influence a behavior (Ajzen, 1991). The distinction is particularly relevant in this paper because we focus on examining a person's willingness to donate (WTD) to the conservation of two endangered marine species, which is a stated intention that is a signal of, and precursor to, the actual behavior of contributing money for conservation.

Few studies have investigated the factors influencing proenvironmental intention and behavior to support marine endangered species conservation. Those that have focused on the determinants of preferences and values derived from stated preference economic valuation methods (Kotchen and Reiling, 2000; Aldrich et al., 2007) ${ }^{2}$. The focal point of these studies is on how environmental concern influences the willingness to pay (WTP) for conservation or protection. WTP is a quantitative measure of economic value. On the other hand, WTD is a qualitative measure of the desire or intent to contribute monetarily. Having a willingness to donate is indicative of, and a precursor to, having a positive WTP. Thus, they are related, but not identical concepts.

Since there are no studies, to our knowledge, that examine the determinants of WTD in a marine conservation context, and WTP is a related concept, we turned to that literature for insights $^{3,4}$. Both Kotchen and Reiling (2000) and Aldrich et al. (2007) determined that environmental concern, as measured by the New Ecological Paradigm ${ }^{5}$, has a strong effect on predicting WTP for the conservation of two endangered species, the peregrine falcon and shortnose sturgeon. Tisdell and Wilson

\footnotetext{
${ }^{2}$ These methods typically involve asking people questions that reveal either directly or indirectly for their preferences or the value they place on a good or service, such as protection of an endangered species (see Lew, 2015).

${ }^{3}$ However, there are several studies that estimate WTP related to the conservation of marine species (e.g., Lew et al., 2010; Boxall et al., 2012; Wallmo and Lew, 2012; Lew, 2015; Wallmo and Lew, 2015) and marine parks (e.g., Peters and Hawkins, 2009) using stated preference methods.

${ }^{4}$ The literature also contains studies that examine factors influencing the intention to carry out environmental friendly activities for the conservation of marine species [e.g., manatees (Aipanjiguly et al., 2003), sea turtle (Kamrowski et al., 2014)]; as well as studies on behavioral intention for topics beyond marine conservation, including conservation of terrestrial threatened and rare fauna (e.g., Jacobson et al., 2003; Perry-Hill et al., 2014), water (e.g., Yazdanpanah et al., 2014), soil (e.g.,Lynne and Rola, 1988), and energy ( Abrahamse and Steg, 2009).

${ }^{5}$ Environmental concern is measured using the New Ecological Paradigm (NEP) scale. The NEP scale measures general environmental concern using responses to 15 likert-scale items (Dunlap et al., 2000). The NEP scale focuses on five core components of environmental concern: limits to economic growth, antianthropocentrism, the fragility of nature's balance, human exemptionalism, and the possibility of potential catastrophic environmental changes affecting people.
} 
(2001) explored how socio-demographic factors affect the WTP of tourists visiting Mon Repos Beach near Bundaberg, Queensland, for the purpose of watching sea turtles. The study showed that on-site experiences with marine wildlife, and whether visitors saw sea turtles, significantly influenced their WTP for species protection.

In this paper, we explore factors influencing tourists' WTD for marine species conservation using survey data of tourists in Ecuador visiting the Galapagos National Park (GNP) and its Marine Reserve to gain insights about tourists' motivations, intentions, and behavior that can aid resource managers and decision makers design more effective ways of funding conservation programs. For this, the Galapagos is a useful region to study due to its economic and political significance in the Eastern Tropical Pacific region in terms of tourism related to marine species. It is the largest MPA in the region, is visited by the greatest number of tourists among archipelagos in the region, and has several marine endangered species found there. Additionally, tourism to the Galapagos has increased steadily over the last decade ${ }^{6}$, making it a useful case study to explore tourists' intentions to support the recovery of marine endangered species in the region. Here we focus on tourists' WTD toward the conservation of two specific marine endangered species found in the Galapagos: the scalloped hammerhead shark (Sphyrna lewini) and the green sea turtle (Chelonia mydas). These are iconic migratory species whose protection would require the expansion of MPA networks and thus benefit the conservation of other species in those networks.

We use discrete choice models to analyze what factors influence the stated intention to donate for the recovery of the endangered green sea turtle and scalloped hammerhead shark. The data for the analysis are from a survey conducted in 2013 with Galapagos tourists. The survey included several questions to identify attitudes and beliefs toward species conservation, levels of concern for specific species, recreational motivations and past donation patterns, as well as individual characteristics, such as age, gender, tourist residency (whether the tourist resides in Ecuador and is therefore "domestic," or is from another country and is a "foreigner"), and other demographics.

\section{MATERIALS AND METHODS \\ Study Setting}

The Galapagos archipelago is one of several island groups in the Eastern Tropical Pacific marine region that extends along the Pacific Coast of the Americas, from the southern tip of the Baja California Peninsula in the north to northern Peru in the south. It consists of 13 major islands and over 100 islets and emergent rocks (Snell et al., 1996) and lies in the eastern tropical Pacific $1000 \mathrm{~km}$ from the coast of continental Ecuador. The Galapagos Marine Reserve (GMR) covers an area of approximately 138,000 $\mathrm{km}^{2}$ (Figure 1).

Approximately $12 \%$ of the marine species in the Eastern Tropical Pacific are threatened with extinction due to overfishing,

\footnotetext{
${ }^{6}$ The number of tourists to the Galapagos has increased at an average rate of $3.7 \%$ per year between 2007 and 2014 (Observatorio de Turismo de Galapagos (OTG), 2015).
}

habitat loss, and changing climatic conditions (Polidoro et al., 2012). Of these threatened species, highly migratory marine species like green sea turtles and scalloped hammerhead sharks are of great concern in the region. Several studies suggest population declines for both species (Seminoff, 2004; Baum et al., 2007). Scalloped hammerhead sharks are facing increasing fishing pressure outside protected adult aggregation sites (Cocos Island in Costa Rica and the Galapagos Islands in Ecuador) and along the slopes of the continental shelf where catch rates of juveniles are high (Baum et al., 2007). Green sea turtles in the region are mainly threatened by coastal development, collection of eggs for consumption, and fisheries bycatch (Seminoff, 2004). As a result of population declines and continued threats, the Eastern Tropical Pacific populations of both species have been listed as Endangered by the International Union for Conservation for Nature (IUCN) on its "Red List" of endangered and threatened species ${ }^{7}$ since 2004 (green sea turtle) and 2007 (scalloped hammerhead shark).

\section{Survey}

Data for the analysis were obtained from a survey of tourists visiting the GNP. There were two versions of the survey: one presented information and asked questions about the green sea turtle (TURTLE version) and the other presented information and questions about the scalloped hammerhead shark (SHARK version). The surveys were developed with input received through 8 focus groups and 12 cognitive interviews held in 2012, which involved 44 tourists and 12 tourist managers. Focus groups and interviews aided in refining the content and presentation of the information provided in the survey, as well as the survey questions themselves.

In the final survey instrument, respondents were presented with information about the IUCN Red List that lists and categorizes endangered species. The main goal was to determine how familiar respondents were with the concepts and mechanisms to define and list endangered species both in their home countries and internationally. Detailed information on the marine endangered species of interest, the green sea turtle or the scalloped hammerhead shark, was then introduced to respondents. This included information about the species' biology, feeding, and breeding behavior; habitat and distribution; and threats, current protection actions, and current extinction risk level and status of its population.

After reading this information, respondents were asked to indicate whether they knew about the different aspects of the species, their level of concern about the future status of the species, and their opinions about potential recovery programs. The surveys also collected personal information from respondents about their recreational motivations to see marine wildlife during their visit to the Galapagos; past donation

\footnotetext{
${ }^{7}$ The IUCN, the International Union for Conservation of Nature, maintains a Red List, which is a comprehensive and objective list of plant and animal species that are at risk of extinction. Risk of extinction refers to the probability of a species becoming extinct in the future. Significant declines in population size and loss of habitat increase the risk of extinction. For both populations in this article, there is at least a $30 \%$ risk of becoming extinct in 60-80 years under current conditions.
} 


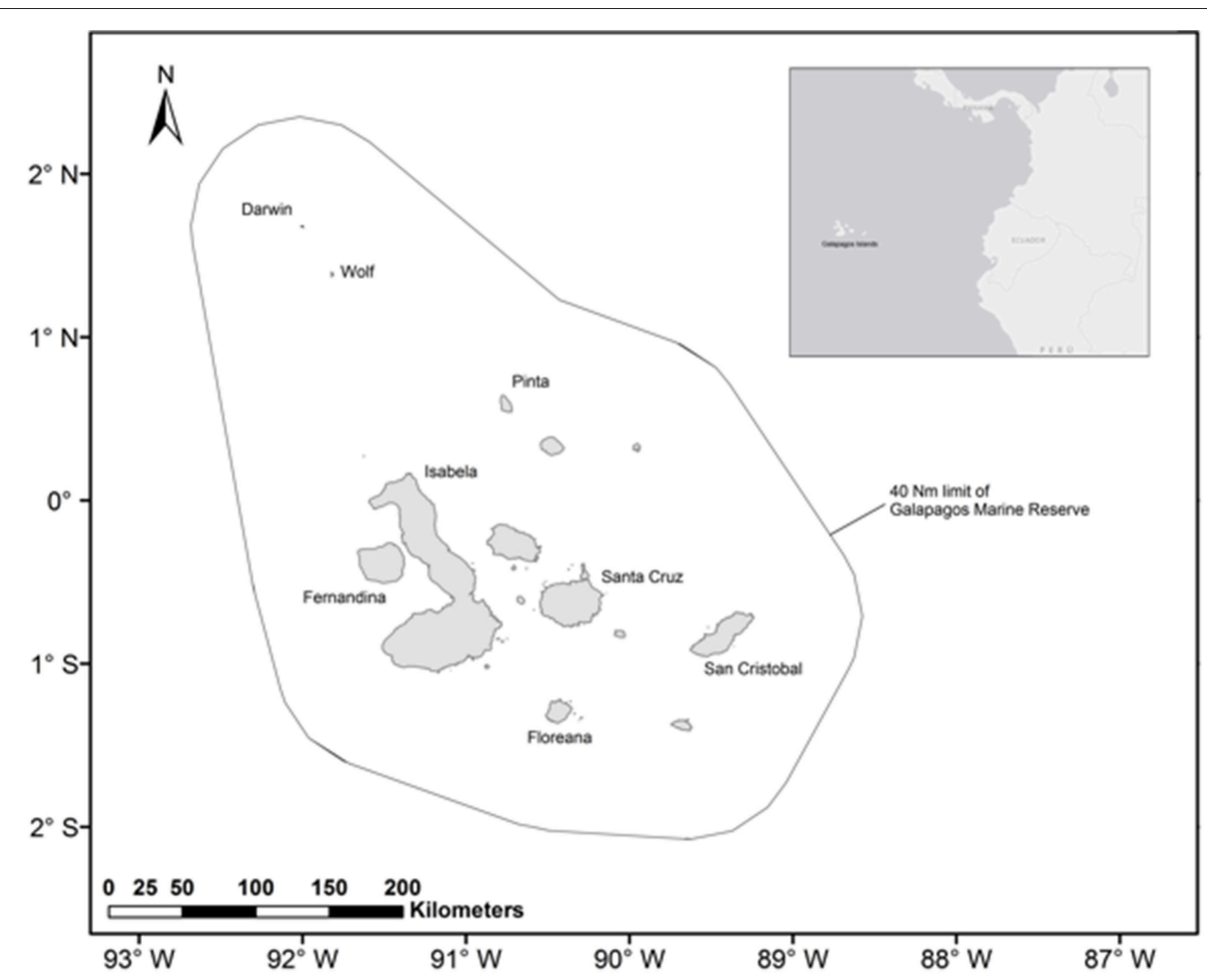

FIGURE 1 | Map of the Galapagos Islands and its marine reserve.

behavior for conservation and non-environmental issues; and socio-economic and demographic information ${ }^{8}$.

The survey also presented a hypothetical, yet plausible, conservation scenario. It described a marine conservation program that would create new MPAs along the coasts of Costa Rica, Panama, Colombia, and Ecuador that would provide direct support for additional protection measures for the green sea turtle (in the TURTLE version) or the scalloped hammerhead shark (in the SHARK version). This new conservation program would complement existing offshore MPAs in the region, including the GNP and Marine Reserve. Due to the migratory nature of the endangered marine species considered here, extending protection to key nursery and feeding coastal areas would reduce their threat status (reduce the risk of extinction and lead to improvement in the IUCN status). An independent non-profit organization with representatives from participating governments and other local institutions in the region would be in charge of overseeing the funds raised through donations.

Respondents were then asked whether they would be willing to donate money to the new conservation program. The WTD response measures the respondents' behavioral intention to donate toward the conservation program and is the focal point of our analysis ${ }^{9}$. Respondents were asked to choose between three

\footnotetext{
${ }^{8}$ Many of these variables are described in more detail in The Analytic Approach section.

${ }^{9}$ The specific wording in the survey was: "Would you donate money to programs that improve the status of the threatened scalloped hammerhead shark?" (or green sea turtle depending on version).
}

possible response alternatives (WTD responses): "no," "yes," and "do not know."10

\section{Survey Implementation}

Before the final survey was implemented, a formal pretest was conducted in 2012 to evaluate and test the survey administration procedures. Subsequently, the final survey was administered ${ }^{11}$ in 2013 to a systematic random sample of tourists leaving the islands from the two airports ${ }^{12}$ serving the Galapagos, Baltra, and San Cristobal. We surveyed during two main periods, MarchApril and July-August, to account for temporal variations in visitation. The survey was a self-administered intercept survey, where randomly selected tourists were intercepted and asked to fill out the survey on their own and return it to the interceptor upon completion.

\section{The Analytic Approach}

We focused our analysis on modeling respondents' WTD toward the recovery of the green sea turtle and scalloped hammerhead

${ }^{10}$ The "don't know" alternative was included after numerous focus group participants expressed that they might be willing to donate and support in the future but they cannot be certain about it at the time of the survey.

${ }^{11}$ In December 2012, the Institutional Review Board Administration (IRB) from the University California, Davis approved survey materials.

${ }^{12}$ Tourist operations have visitors enter and depart the Galapagos through either the Baltra airport or San Cristobal airport. Surveys were implemented at both airports and during different times of the year to minimize coverage bias and to optimize (with a limited budget) the chances of obtaining a sample with representation from tourists from the Northern Hemisphere and Southern Hemisphere who visit the Galapagos at different times of the year. 
shark. To this end, we use random utility maximization (RUM) based discrete choice models to analyze responses that indicate respondents' intention to donate to the conservation scenario described in the survey. In the RUM approach, when faced with $J$ alternatives, respondent $i$ chooses the alternative that yields the largest utility from among the set of $J$ alternatives (in this case $J$ $=3$ : "yes," "no," "do not know"). The utility of the jth alternative $\left(\mathrm{U}_{i j}\right)$ is composed of an observable deterministic component $\left(\mathrm{V}_{i j}\right)$ and a stochastic component $\left(\varepsilon_{i j}\right)$ that is known to the individual, but not the researcher (McFadden, 1974). Thus, we can model the probability that respondent $i$ chooses the $j$ th alternative as:

$$
\operatorname{Pr}_{i}[\text { choose } j]=\operatorname{Pr}\left(\mathrm{U}_{i j} \geq \mathrm{U}_{i k}, \forall j \neq k\right)
$$

Following the common assumption that errors are independently and identically Gumbel distributed, we get the familiar multinomial logit model (McFadden, 1974), with corresponding probabilities of the form (Greene, 2011):

$$
\operatorname{Pr}_{i}[\text { choose } j]=\frac{\exp \left(V_{i j}\right)}{\sum_{k=1}^{J} \exp \left(V_{i k}\right)}, \forall j, k \in J
$$

In this application, $\mathrm{V}_{i j}$ is assumed to be a linear additive function of the independent explanatory variables ${ }^{13}$ characterizing respondent $i$ 's utility. Two main socio-psychological theoretical frameworks informed the selection of variables for the utility specification. The first is the Theory of Planned Behavior or TPB (Ajzen, 1991), which postulates that the intention to perform a certain behavior is the main predictor of that behavior. According to TPB, behavioral intention is determined by attitudes toward the behavior (positive or negative evaluation of performing the behavior), subjective norms (perception of social pressure from reference groups to perform the behavior), and perceived behavioral control (perceived ease or difficulty of performing the behavior). The other relevant conceptual framework is the Value-belief-norm (VPN) theory developed by Stern and colleagues (Stern et al., 1999; Stern, 2000), which postulates that pro-environmental behavior is determined by five factors: (a) general personal values (e.g., altruistic, egoistic); (b) ecological worldview ${ }^{14}$; (c) personal beliefs on adverse consequences for valued objects, (d) personal beliefs on perceived ability to reduce threat; and (e) personal norms for pro-environmental action. The VPN model explicitly accounts for beliefs about the consequences of human-environment relationships and how the individual can actually reduce threats. These particular beliefs could be shaped by information and findings from science.

These two theoretical frameworks suggest survey questions related to environmental attitudes and personal beliefs should help explain WTD. Both attitudes and beliefs are the core elements that will influence the intention to perform a behavior according to either the TPB or VPN. Environmental attitudes have been defined as a "psychological tendency expressed by evaluating the natural environment with some degree of favor

\footnotetext{
${ }^{13}$ Groups of explanatory variables are represented by $X$ vectors in the text that follows.

${ }^{14}$ Environmental worldviews are commonly measured by the NEP Scale (described in earlier note).
}

or disfavor" (Milfont and Duckitt, 2010, p. 80). Environmental attitudes are usually represented by environmental concern ${ }^{15}$ $\left(\boldsymbol{X}^{\text {attitudes }}\right)$ and for this application we identify three measures: one describing how important protecting endangered species is in general; the level of concern about the specific marine endangered species in the survey; and the level of concern about the effectiveness of the conservation program. We also include two types of personal beliefs $\left(\boldsymbol{X}^{\text {beliefs }}\right)$ : a norm belief and a control belief. In general, norm beliefs are indicators of how the individual's behavior is influenced by what should I do or by what others think I should do (Schwartz, 1977; Ajzen, 1991). In the survey, tourists were asked to indicate their level of agreement to the norm belief that protection for the marine endangered species should be paid only by residents of the region. The control belief was framed according to the VPN theory (Stern et al., 1999) as a perceived ability to reduce an environmental threat; in this case, the extinction of an endangered species and respondents were asked to indicate their level of agreement with donating for the protection of the species even though it is threatened and may still become extinct in the future.

Besides psychological factors, Stern (2000) argues that studies to understand predisposition to behavior often overlook important factors, specifically personal characteristics (e.g., personal habits, interest for, and impact of experiences) and context-related factors (specific features of the environment where the behavior will take place; e.g., incentives and available information). To capture these individual-specific factors we include the following explanatory variables: previous knowledge on endangered species $\left(\boldsymbol{X}^{\text {knowledge }}\right)$, past donation behavior $\left(\boldsymbol{X}^{\text {donation }}\right)$, and personal motivations ${ }^{16}$ to see marine species $\left(\boldsymbol{X}^{\text {motivation }}\right)$, all of which are relevant to the conservation scenario presented. Respondents were asked about their knowledge of endangered species ( $\boldsymbol{X}^{\text {knowledge }}$ ) at two scales: (a) general familiarity with the listing process and with regulations on endangered species in tourists' home countries; and (b) specific knowledge about the ecology, threats, and protection measures taken to protect the specific marine endangered species in the survey. In addition, several variables were included in the model to assess each respondent's experience with donating money $\left(\boldsymbol{X}^{\text {donation }}\right)$, specifically whether the respondent had donated time or money in the past to a conservation organization, had donated money to a marine conservation program specifically, and had donated money to specific causes in the last 5 years. The specific causes included poverty, education, environment, and the arts. Finally, tourists were also asked about the importance of seeing marine animals as a motivation for visiting the Galapagos Islands $\left(\boldsymbol{X}^{\text {motivation }}\right)$. All tourists were presented with four groups of marine species to rate their motivation to see them during the trip: sharks, sea turtles, sea lions, and marine iguanas (all of these

\footnotetext{
15 Environmental concern is a broad term that refers to beliefs and attitudes related to the seriousness and importance of environmental issues and commonly used to measure attitudes toward environment and conservation (Dunlap and Jones, 2002; Milfont and Duckitt, 2010).

${ }^{16}$ Several empirical studies assessing factors influencing predisposition to proenvironmental behavior in tourists have confirmed the significant influence of visitors' recreational interest toward the environment (Kerstetter et al., 2004; Thapa, 2010; Kil et al., 2014).
} 
species groups consist of at least some species listed under the IUCN Red List).

Socio-economic and demographic data were also included as control variables $\left(\mathrm{X}^{\text {demographics }}\right)$. Likelihood ratio tests suggested that education, level of employment, region of residence, and whether the respondent was a retiree or not were not statistically significant and were thus excluded from the final models ${ }^{17}$. Household income, gender, age, and a binary variable for whether the tourist is from Ecuador or not (origin) were included as explanatory variables. Thus, the utility function for the $i$ th individual and $j$ th choice alternative was specified as:

$$
\begin{aligned}
V_{i j}= & \alpha_{j}+\beta_{j} X_{i}^{\text {attitudes }}+\delta_{j} X_{i}^{\text {beliefs }}+\phi_{j} X_{i}^{\text {knowledge }}+\lambda_{j} X_{i}^{\text {donation }} \\
& +\gamma_{j} X_{i}^{\text {motivation }}+\varphi_{j} X_{i}^{\text {demographics }}
\end{aligned}
$$

where, $\alpha$ is a scalar parameter (intercept), and $\beta, \delta, \Phi, \lambda, \gamma$, and $\varphi$ are unknown coefficient vectors that are specific to the associated response ("no," "yes," and "do not know"); that is, there is a separate set of parameter vectors for each response. Identical explanatory variables are included in both the TURTLE and SHARK models.

We estimate separate multinomial logit models for each of the two survey versions (TURTLE and SHARK) using maximum likelihood estimation in STATA 14.0. A pooled version that combines data from the SHARK and TURTLE versions was also estimated with a dummy variable to identify whether or not WTD is affected by the version of the survey, which is a proxy for the effect due to the species ${ }^{18}$.

\section{RESULTS}

\section{Survey-Descriptive Statistics}

The survey achieved an overall cooperation rate of $94 \%$ across the two main survey versions ${ }^{19}$. The total number of complete and valid ${ }^{20}$ surveys used for the analysis was 701 (367 SHARK and 334 TURTLE surveys) ${ }^{21}$. Across the samples, the mean age of respondents was 44 years, and $42 \%$ of respondents were male (see descriptive statistics in Table 1). Approximately 63\% were foreigners (reside outside Ecuador),

\footnotetext{
${ }^{17}$ Although we expected that education and level of employment were predictors for WTD, their low statistical significance could be explained by their correlation with income or by a low variation across the sample if we consider the average profile of Galapagos tourists (Table 2). A binary variable for "Retired", as a specific level of an employment characteristic of some Galapagos tourists, was shown to be insignificant as well. These results might indicate that income captured most of the explained variation. In addition, variables related to whether the tourist actually saw the endangered marine species in the survey as part of their most recent trip to Galapagos were also found not to be statistically significant.

${ }^{18}$ However, a likelihood ratio test indicated that the data should be estimated separately instead of pooled (test statistic was 77.62, $\mathrm{p}<0.001$ ).

${ }^{19}$ Cooperation rates are calculated as the number of completed surveys divided by the number of tourists intercepted and asked to participate. Separate cooperation rates for each version were 94.5\% (TURTLE version) and 93.5\% (SHARK version).

${ }^{20}$ Valid surveys were those that were not missing observations to key variables for the analysis, and were not identified as "protest" respondents based on their responses to follow-up questions and open-ended comments.

${ }^{21}$ The margin of error for the two samples (and a binary response) are $5.36 \%$ (TURTLE) and 5.11\% (SHARK) considering a tourist population of 204,000 for 2013 (official statistic) and a confidence level of $95 \%$.
}

\begin{tabular}{|c|c|c|c|}
\hline Socioeconomic variable & $\begin{array}{c}\text { Turtle } \\
(N=334)\end{array}$ & $\begin{array}{c}\text { Shark } \\
(N=367)\end{array}$ & $\begin{array}{c}T \text {-test } \\
\text { statistic }\end{array}$ \\
\hline GENDER & & & -1.16 \\
\hline Female (\%) & 61 & 56 & \\
\hline EDUCATION CATEGORY & & & -0.34 \\
\hline High school (\%) & 7 & 11 & \\
\hline Some university (\%) & 12 & 11 & \\
\hline Undergraduate degree (\%) & 37 & 33 & \\
\hline Graduate work/degree (\%) & 44 & 45 & \\
\hline EMPLOYMENT CATEGORY & & & -0.47 \\
\hline Full-time employed (\%) & 61 & 60 & \\
\hline Part-time employed (\%) & 11 & 11 & \\
\hline Student (\%) & 5 & 5 & \\
\hline Retired (\%) & 12 & 12 & \\
\hline Unemployed/Unpaid (\%) & 4 & 6 & \\
\hline REGION OF ORIGIN & & & 1.29 \\
\hline Asia/Africa (\%) & 2 & 2 & \\
\hline Europe (\%) & 21 & 17 & \\
\hline Latin America (\%) & 46 & 49 & \\
\hline North America (\%) & 28 & 29 & \\
\hline Oceania (\%) & 4 & 3 & \\
\hline ORIGIN GENERAL & & & 1.44 \\
\hline Domestic (\%) & 33 & 38 & \\
\hline Foreigner (\%) & 67 & 62 & \\
\hline AGE CATEGORY & & & 0.44 \\
\hline Median Age & 41.5 & 44.0 & \\
\hline Mean Age & 43.6 & 43.9 & \\
\hline INCOME (2012 \$US DOLLARS) & & & -1.21 \\
\hline Median Income & 60.0 & 47.2 & \\
\hline Mean Income & 75.6 & 70.7 & \\
\hline
\end{tabular}

TABLE 1 | Socio-demographic variables.

and 37\% came from mainland Ecuador. Respondents from North America, particularly the United States, accounted for $28 \%$ of all respondents. European respondents accounted for another $20 \%$, while only $5 \%$ came from Asia, Africa, or Oceania. Eighty percent of the respondents had at least a 4-year university degree or higher, and more than $60 \%$ indicated having full-time employment. Across all respondents, mean household income was $\$ 73,000$ USD with a standard deviation of $\$ 64,800$ USD. There was a considerable difference in household income levels between foreign (mean annual income of \$101,400 USD) and domestic (mean annual income of $\$ 21,800 \mathrm{USD}^{22}$ ) respondents in the sample. The numbers suggest a common profile of tourists visiting the GNP: well-educated and higher income individuals. Student's $t$-tests confirm that the samples for each survey version (SHARK and TURTLE versions) were not statistically significantly different across the demographic characteristics.

\footnotetext{
${ }^{22}$ According to official statistics from the Ecuadorian Institute of Censuses and Statistics, average annual household income in 2011 was approximately $\$ 9000$ and has not increased significantly during the last 3 years. This figure shows that domestic tourists visiting the Galapagos have income levels that are much higher than the average income level in the country.
} 
TABLE 2 | Factors influencing WTD-descriptive statistics.

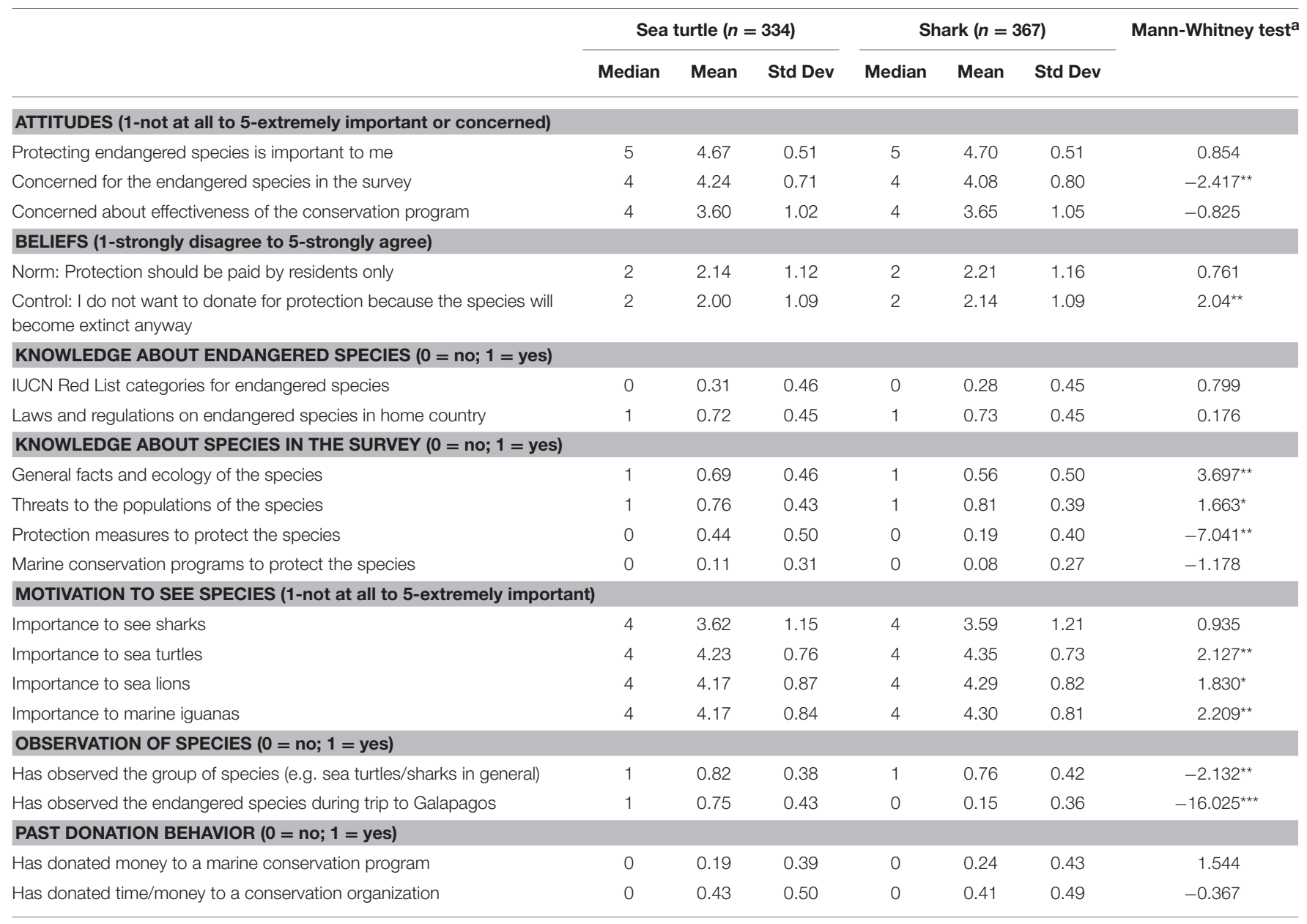

${ }^{a}$ Reports the significance of the Mann-Whitney test; statistically significant differences between distributions are indicated at the $1 \%{\left({ }^{* *}\right)}^{*}, 5 \%\left(^{* *}\right)$, and $10 \%\left(^{(*)}\right.$ levels.

Across the sample, only about $30 \%$ of survey respondents had heard of the global IUCN Red List, but $72 \%$ indicated that they were familiar with laws and regulations pertaining to endangered species in their home countries (Table 2). Survey respondents to both versions of the survey also indicated that protecting endangered species is important to them (mean of 4.68 on a 5point Likert scale, where 1 represents not at all important and 5 extremely important). For both survey versions combined, the majority of respondents had heard about the species presented in the survey (62\%) and about the natural and human-related threats they face (79\%). The results show that statistically more respondents know about protection efforts for the green sea turtle compared to those for the scalloped hammerhead shark ( $44 \%$ compared to $19 \%$ for TURTLE and SHARK, respectively). On average, survey respondents were "very concerned" about the species' future status given the information provided about each species in the survey. The mean concern level for the endangered sea turtle (4.24) is statistically higher than that for the scalloped hammerhead shark (4.08) at the $5 \%$ level of significance.

The majority of respondents indicated they felt it was at least a "very important" ( 4 on a 5 -point scale from $1=$ not at all important to $5=$ extremely important) motivation for their Galapagos trip for them to see sharks (59\%), sea turtles (87\%), sea lions (83\%), and marine iguanas (84\%). In terms of actually observing the species of interest in the surveys during their trip, more than $70 \%$ had observed the green sea turtle as part of the trip to the Galapagos, compared to only $17 \%$ who had observed scalloped hammerhead sharks ${ }^{23}$.

\section{WTD Modeling Results}

For the SHARK sample, 25\% responded "no" to the question asking whether they would be willing to donate to the conservation program, while $34 \%$ said "yes" and $38 \%$ stated they "do not know" in the question. Nineteen percent of the TURTLE sample responded "no", while 43\% said "yes" and 38\% indicated they "do not know" whether they would donate toward the program.

\footnotetext{
${ }^{23}$ As one reviewer noted, reported sightings of the green sea turtle may be inaccurate given the potential for respondents confusing the green turtles with other sea turtle species. However, the green sea turtle is the most common sea turtle seen in the Galapagos. The survey provides information and pictures of the species, which should also have aided in answering this question more accurately.
} 
The "no" response was selected as the base alternative for both the TURTLE and SHARK models, resulting in parameters being estimated for the utility functions associated with the other two response functions "yes" and "do not know" (Table 3). The likelihood ratio index, a pseudo- $\mathrm{R}^{2}$ measure of goodness-of-fit (Maddala, 1983), was 0.26 for the TURTLE model and 0.21 for the SHARK model. These LRI values suggest that both models are statistically significant (i.e., the parameters are jointly significant).

Except for the belief variables ${ }^{24}$, positive coefficients indicate that higher levels of the variable lead to a higher probability of answering "yes" or "do not know" to the intention to donate toward the recovery of the species. Conversely, negative coefficients suggest that the explanatory variable reduces the likelihood of a "yes" or "do not know" response.

\section{Factors that Influence a "Yes" Response on WTD \\ Psychological Factors}

We find that environmental attitudes are statistically significant and influence WTD only when they measure the concern for the specific marine endangered species in the survey. Consistent with our expectations, respondents who are more concerned about the endangered species are more likely to donate toward its recovery, all else being equal (Table 3). Results also indicate that attitudes toward protecting endangered species in general do not influence the WTD for either endangered species. In addition, respondents' attitudes toward the conservation program, specifically the level of concern about its effectiveness, only influence the probability of being willing to donate in the SHARK model but not in the TURTLE model.

The estimated coefficients representing personal beliefs are negative and statistically significant for both survey versions. The more agreement with the norm belief that only residents should pay for protection of both marine endangered species, the lower the probability of a positive intention to donate for conserving the species. In other words, respondents who believe the species' protection should not be the sole responsibility of residents are more likely to donate. Moreover, respondents who believe that their donations can reduce the risk of extinction of the endangered species are more likely to be willing to donate in the future.

Seeing, or feeling it was important to see, marine endangered species in the Galapagos influenced intentions to support the marine conservation program depending on the species in the survey. Although survey respondents reported a high level of interest to see sea turtles while in the Galapagos (Table 2), this motivation does not appear to influence their decision to support recovery programs, as the parameter on "importance to see sea turtles" was not statistically different from zero (Table 3). Moreover, likelihood ratio tests failed to reject the null hypothesis that the parameters representing recreational motivations are jointly zero for the turtle model. In contrast, for the endangered scalloped hammerhead shark, the more

\footnotetext{
${ }^{24}$ Due to the wording of these questions, the coefficients have interpretations that are different from those of other explanatory variables. Please refer to the section on "Psychological drivers" below for a detailed explanation.
}

importance respondents placed on seeing sharks, the higher the probability of answering "yes" when they were asked for their WTD for shark conservation. This is consistent with our prior that tourists who are willing to donate toward the recovery of endangered sharks are those who have a particular interest in the species; specifically, divers whose primary motivation is diving with schools of sharks in the archipelago.

\section{Socio-Demographic Variables}

The results of a likelihood ratio test suggest there is a statistically significant joint effect of socio-demographic variables on WTD for the recovery of the two marine endangered species (Table 4). However, the individual statistical significance of individual variables differs between the two models. Whether a tourist is from Ecuador or not (origin) has a statistically significant influence on the probability to donate for sea turtle conservation, but not for shark conservation (Table 3). Our results thus indicate that domestic (Ecuadorian) respondents have a significantly higher probability of being willing to donate to the recovery of sea turtles than foreigners, all else being equal. Household income ${ }^{25}$, by contrast, appears to influence the intention to donate only for the recovery of the endangered hammerhead shark. Contrary to expectations and other studies involving endangered species (Aldrich et al., 2007; Choi and Fielding, 2013), the income effect on the probability to donate for shark conservation is negative. Thus, respondents with higher income levels were less likely to donate toward the recovery of the endangered hammerhead shark (Table 3); and this relationship is similar for domestic and international visitors. Other socio-demographic variables, including gender and age, do not influence the probability to donate toward the protection of either endangered species ${ }^{26}$.

\section{Other Individual-Specific Variables}

Our results show that factors other than psychological and socio-economic characteristics of tourists in Galapagos have a statistically significant effect on WTD. Past donation behavior is a determinant of the intent to donate to the conservation of both marine endangered species (Table 3 ). The joint significance of all past donation-related variables is high (at the 1\% level) for both the TURTLE and SHARK models. The results indicate that respondents who have specifically donated to causes related to environmental and animal welfare in the last 5 years are more likely to be willing to financially support the recovery of the endangered green sea turtle and the scalloped hammerhead shark, which is consistent with our a priori expectations. Interestingly, although more than $40 \%$ of the respondents visiting the Galapagos have participated or been a member of a conservation organization, this does not seem to influence their intention to donate specifically for marine endangered species conservation. Past donations specifically to marine conservation

\footnotetext{
${ }^{25}$ Multiple income variables, including interactions of income with region of residency and nationality, were used when testing model specification. However, these variables led to similar qualitative results. Likewise, interaction variables between income and nationality did not yield statistically significant results.

${ }^{26}$ Several model specifications were initially tried that included variables to account for effects due to tourists' region of residency (e.g., Europe, North America, or other), but these effects did not seem to be statistically significant.
} 
TABLE 3 | Multinomial logit results.

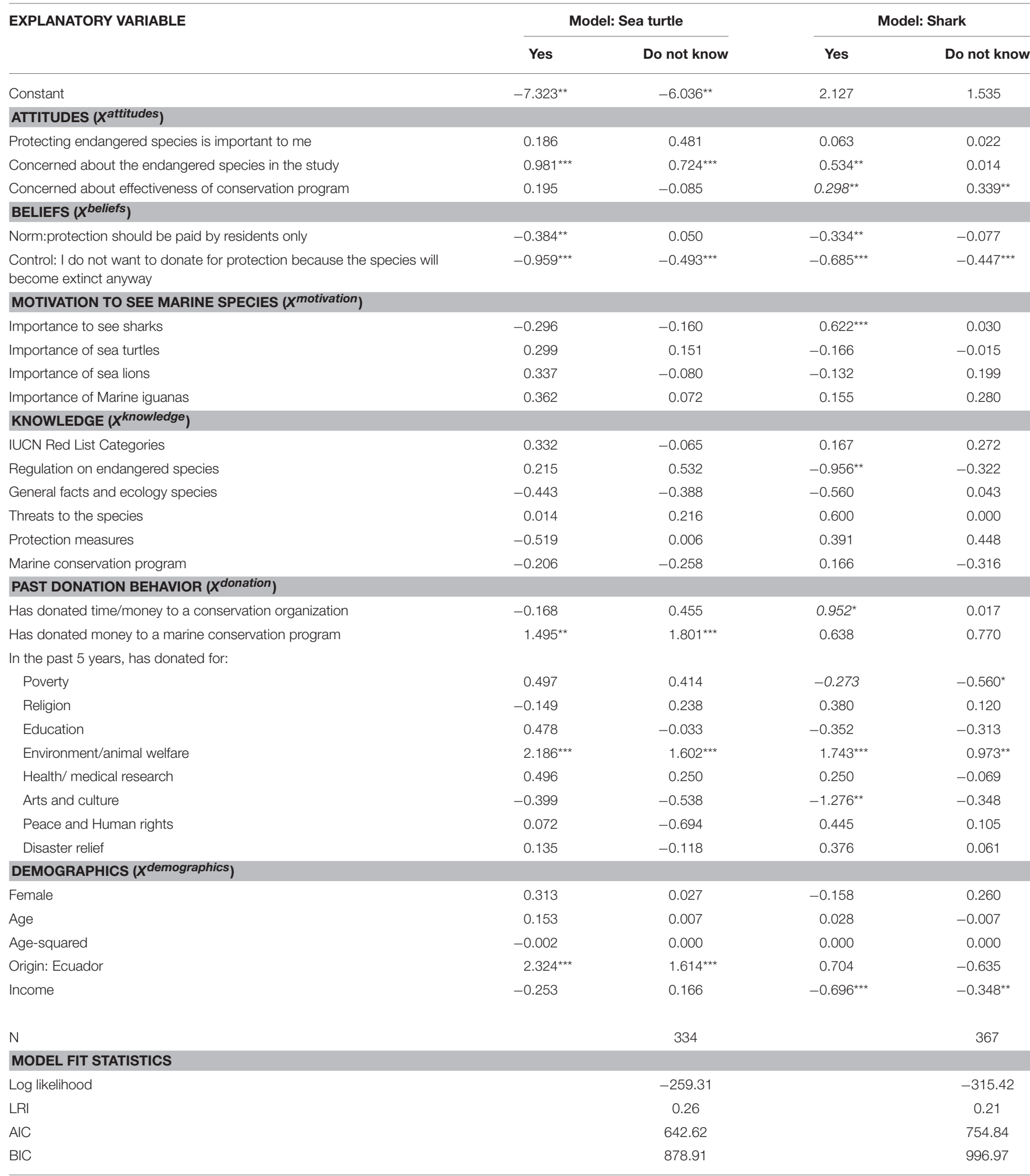

Statistical significance of parameters: *, statistically different from zero at the $10 \%$ level; **, statistically different from zero at the $5 \%$ level; ${ }^{* * *}$, statistically different from zero at the $1 \%$ level. 
TABLE 4 | Joint significance of the explanatory variables of the multinomial logit model.

\begin{tabular}{|c|c|c|}
\hline & \multicolumn{2}{|c|}{$\begin{array}{l}\text { Likelihood ratio } \\
\text { test statistic }{ }^{\star, \star *}\end{array}$} \\
\hline & $\begin{array}{c}\text { Sea turtle } \\
\text { model }\end{array}$ & $\begin{array}{l}\text { Shark } \\
\text { model }\end{array}$ \\
\hline All parameters for attitudes and beliefs are zero & $71.46^{\star \star \star}$ & $47.02^{\star \star \star}$ \\
\hline All parameters for motivations are zero & 12.56 & $24.12^{* * *}$ \\
\hline All parameters for past donation behavior are zero & $49.04^{* * *}$ & $50.04^{* * *}$ \\
\hline All parameters for knowledge are zero & 8.42 & 15.37 \\
\hline All parameters for demographics are zero & $33.35^{\star \star \star}$ & $37.54^{\star * \star}$ \\
\hline
\end{tabular}

Parameters are jointly different from zero at the $10 \%$ level $\left(^{\star}\right)$, at the $5 \%$ level $\left({ }^{\star *}\right)$, at the $1 \%$ level $\left.{ }^{* \star *}\right)$.

programs significantly influence WTD only for the TURTLE model. Thus, the main driver of WTD is the actual past donation behavior, and particularly past donations related to the environment and its goods and services.

In contrast to personal donation habits, prior knowledge about endangered species does not significantly affect WTD. This is true for both levels of knowledge assessed in the study: general knowledge about listed IUCN categories and specific knowledge about the endangered green sea turtle and hammerhead shark. Likelihood ratio tests could not reject the null hypothesis that prior knowledge variables are jointly zero. The only exception to this result is in the SHARK model, where prior knowledge about regulations on endangered species (generally) in their home country has a statistically significant and negative influence on respondents' WTD.

\section{Species Effects}

In comparing preferences between the endangered sea turtle and hammerhead shark models, we find evidence of a species effect related to the green sea turtle. The pooled version of the model combines data from the TURTLE and SHARK versions and allows us to assess whether there is a difference between WTD between the versions (Appendix Table 1). Note that although the species effect parameter will capture all the differences between the survey versions, the two versions were identical except in specific information on each species; therefore, other differences between versions are expected to be negligible. The coefficient on a dummy variable for the green sea turtle version in the pooled model is positive and significant (coefficient $0.911, p=0.001$ ), which suggests a relative preference toward the green sea turtle over the scalloped hammerhead shark in terms of WTD.

\section{Comparing the "Yes" and the "Do Not Know" Response Functions}

Our findings suggest that factors that influence WTD are similar between respondents who are willing to donate ("yes") and respondents who are uncertain ("do not know") if they will donate toward the recovery of the endangered sea turtle. That is, there are qualitative similarities between parameters associated with the "Yes" and "Do not know" responses for each species model (Table 3). Statistical significance levels of the coefficients of the "yes" and "do not know" response functions for the TURTLE model are similar. Some differences do exist, however, between these estimated functions for the SHARK model. For instance, the effects of the explanatory variables, level of concern about the endangered species, the norm belief about "only residents should pay for protection," and knowledge about regulations on endangered species, are statistically significant only for those respondents who answer positively to the WTD question.

\section{DISCUSSION}

In this study, we investigated factors that influence tourists' intentions to donate toward the recovery of two marine endangered species in the GNP. Our results suggest that environmental attitudes, personal beliefs, and past donation behavior affect tourists' stated intentions. Consistent with the TPB (Ajzen, 1991) and VPN (Stern et al., 1999) sociopsychological theoretical frameworks, we found that specific attitudes and beliefs toward the environmental good (in this case marine endangered species) matter. Tourists who are more concerned about the extinction of the two marine endangered species in the future are more likely to be willing to donate toward their recovery. Moreover, the stronger the personal beliefs about the shared responsibility of protecting the species and that actions to protect the species should be done, the higher the probability of tourists' intention to donate for the conservation of these species.

The estimated effect socio-demographic factors had on WTD did not meet our a priori expectations. Contrary to other studies involving endangered species (Aldrich et al., 2007; Choi and Fielding, 2013), the income effect on the probability to donate for shark conservation is statistically significant but negative, meaning those who are more wealthy are less likely to donate. A possible explanation for this result is that tourists interested in supporting shark conservation are part of a small group of visitors with specific recreational interests and motivations for this particular group of marine species. Moreover, the majority of tourists, and those with higher income profiles, might not be interested in shark conservation specifically, but rather have broader conservation interests that would drive the model results. In the green sea turtle's case, the statistical insignificance of the income variable might be caused by the correlation between household income and origin of tourists in the sample ${ }^{27}$. Additionally, the parameter on tourist origin may be picking up whatever effect income has on WTD. Considering that tourists visiting the Galapagos are in general wealthier than average individuals, the low variation in (higher) income levels across the sample might explain the low statistical significance of household income.

This study confirms the importance of individual-specific explanatory variables emphasized in modern models of proenvironmental behavior (Stern, 2000), at least in this application. Specifically, we found that past donation behavior is a significant factor that positively influences WTD. The results of the

${ }^{27}$ Correlation coefficients between household income and tourist origin are -0.63 for the TURTLE version and -0.67 for the SHARK version. 
behavioral model suggest that tourists who have donated in the past to causes related to the environment, animal welfare, and marine conservation are more likely to be willing to donate to conservation programs for the green sea turtle and the hammerhead shark, all else being equal. Surprisingly, neither knowledge about endangered species nor general recreational motivations to see marine species during their visit influences WTD in this study. This was contrary to our expectations and to modern psychological models (Stern, 2000), which emphasize the influence of context-dependent variables on the predisposition to perform a pro-environmental behavior. Nevertheless, the statistically insignificant role of knowledge about the marine endangered species is similar to results of previous empirical studies on endangered species (Kotchen and Reiling, 2000; Aldrich et al., 2007). The one exception to this finding suggests that tourists who are more informed about endangered species regulations in their home countries tend to be less willing to donate money toward the protection of the scalloped hammerhead shark in the Galapagos and Eastern Tropical Pacific. This knowledge does not have the same effect on WTD for the green sea turtle recovery. Together, the discussion above suggests that personal factors, such as specific past donation behavior and specific knowledge about laws or regulations to protect endangered species, seem to affect tourists' WTD to the conservation of the two species.

In addition to the several psychological, socio-demographic, and personal factors influencing stated intentions, we found evidence of a species effect on $\mathrm{WTD}^{28}$. This "species effect" suggests that tourist visiting the Galapagos and the Eastern Tropical Pacific have a stronger preference to donate to the recovery of the green sea turtle. One potential explanation of the species effect is the differential perception tourists may have of these species: sea turtles may be viewed as more charismatic and friendly sea animals, while sharks may be viewed as scary and dangerous. Additionally, tourists who are knowledgeable about or wish to see the scalloped hammerhead shark tend to be more willing to donate toward protection of this species. However, those factors do not appear to influence WTD toward protection of the green sea turtle. In combination, these things suggest that tourists vary in their personal preferences toward each marine endangered species and their protection. Consequently, it is important to recognize these differing preferences when assessing intended or actual behavior toward their conservation. Indeed, previous studies on U.S. endangered species have suggested that the charismatic nature of a species influences the amount spent on its protection (Metrick and Weitzman, 1996) and on people's WTP for protection efforts (Richardson and Loomis, 2009).

This study represents one of the few studies to investigate the factors influencing WTD for the recovery and protection of marine endangered species. It supports previous empirical evidence about the influence of environmental attitudes on

${ }^{28}$ Admittedly, the species effect is measured with a parameter that captures all differences between the survey versions. Therefore, it is possible that the species effect may embed other tourist preference differences affected by other differences in the surveys. However, given the two survey versions were constructed to be identical except for the species-specific information, the likelihood of this occurring is small. a related concept, WTP for endangered species conservation (Kotchen and Reiling, 2000; Aldrich et al., 2007; Spash et al., 2009; Choi and Fielding, 2013). Besides confirming a significant relationship between attitudes and intention-to-donate for the recovery of two marine endangered species, the current study contributes to the empirical literature by evaluating other personal behavioral and context-dependent factors.

However, there are some limitations of the study. First, we limited the analysis to two marine endangered species and to a specific targeted population of these species, the Eastern Tropical Pacific populations. Thus, our results may not be generalizable to other species or to other populations in different marine regions. In addition, our modeling approach assumes that respondents were considering only one of two marine endangered species, either the green sea turtle or the scalloped hammerhead shark, when they answered the WTD question. This, however, may not be true for some respondents who might be linking the conservation program to other marine species. In this case, WTD responses might be based on more than an individual's concern for the species in question (this is commonly referred to as an embedding effect) ${ }^{29}$. However, we leave an investigation into this potential source of bias for future research. Geographically, the study focused only on Galapagos tourists. As such, to the extent visitors to other islands in the Eastern Tropical Pacific differ from Galapagos tourists in terms of their willingness to donate for species conservation, the results may not be generalizable beyond the targeted population. In addition, the study surveyed tourists about their intention to donate immediately after they finished their visit to Galapagos, which may potentially bias their answers toward a future donation behavior. However, recent studies have shown a smaller than expected positive long-term pro-environmental behavior after wildlife-watching trips. For instance, Ballantyne et al. (2011) found out that only $7 \%$ of visitors reported adopting a pro-environmental behavior as a result of a whale- and sea turtle-watching visit when surveyed 4 months after the visit. Therefore, our results may represent an upper bound on tourists' intention to donate. Finally, we note that this study focused on analyzing factors affecting tourists' behavioral intention to donate, not on how much they would be willing to donate (their willingness to pay), which is left for future research $^{30}$.

From a policy perspective, the current study highlights the potential application of behavioral results to efforts to fund conservation of marine endangered species in the Eastern Tropical Pacific marine region. Both the endangered green sea turtle and the scalloped hammerhead shark are considered "umbrella species" in conservation efforts-increasing protection of their expansive distribution and range will benefit other species (Roberge and Angelstam, 2004). Moreover, MPAs, and in particular the GNP, are important tourist attractions.

\footnotetext{
${ }^{29}$ In our context, an embedding effect occurs when an individual's response to the WTD question is based on an assumption made by the individual that more than just the species in question (green sea turtle or scalloped hammerhead shark) will be helped by the conservation program.

${ }^{30}$ See Lew (2015) for further discussion of willingness to pay studies related to endangered marine species, the methods used in these studies, and willingness to pay estimates for other endangered marine species.
} 
Increasing marine ecotourism represents an opportunity to provide funds for the conservation of marine biodiversity and coastal livelihoods through visitation fees or donations (Halpenny, 2003; Mayes et al., 2004). The findings of the study provide empirical evidence and insights about the factors that drive tourists visiting the Galapagos archipelago to be willing to contribute monetarily to marine conservation in the region, and specifically to the two marine endangered species under study. This information can be used by resource agencies to understand the true potential and feasibility of alternative funding mechanisms for conservation programs in the region.

As suggested by the study findings, certain profiles of visitors to the GNP are willing to contribute toward the recovery of the threatened populations of the green sea turtle and the scalloped hammerhead shark in the Eastern Tropical Pacific. In fact, our results show that there are heterogeneous preferences among tourists interested in donating for the two marine endangered species, which can be used when designing funding mechanisms for marine conservation. For instance, funding efforts can focus on tourists who have strong preferences for environmental-related causes by targeting them at more environmentally-friendly lodging places or cruises. Partnering with institutions working on marine conservation programs and with diving agencies is also a potential mechanism to enhance fundraising opportunities for resource agencies. In addition, resource agencies may wish to focus fundraising campaigns on protection of the endangered green sea turtle, given it has a stronger positive effect on stated donation behavior. Given the overlapping habitat of the green sea turtle with the scalloped hammerhead shark and other species, protection of the green sea turtle would still have a positive effect on conservation of other species.

At the broader regional level, the findings of this study are timely for the debate over alternative funding mechanisms being considered for the Eastern Tropical Pacific Marine Corridor (CMAR), a governmental initiative to create and promote

\section{REFERENCES}

Abrahamse, W., and Steg, L. (2009). How do socio-demographic and psychological factors relate to households' direct and indirect energy use and savings? J. Econ. Psychol. 30, 711-720. doi: 10.1016/j.joep.2009. 05.006

Aipanjiguly, S., Jacobson, S., and Flamm, R. (2003). Conserving manatees: knowledge, attitudes, and intentions of boaters in Tampa Bay, Florida. Conserv. Biol. 17, 1098-1105. doi: 10.1046/j.1523-1739.2003.01452.x

Ajzen, I. (1991). The theory of planned behavior. Organ. Behav. Hum. Decis. Process. 50, 179-211. doi: 10.1016/0749-5978(91)90020-T

Aldrich, G., Grimsrud, K., Thacher, J., and Kotchen, M. (2007). Relating environmental attitudes and contingent values: how robust are methods for identifying preference heterogeneity? Environ. Resour. Econ. 37, 757-775. doi: 10.1007/s10640-006-9054-7

Ballantyne, R., Packer, J., and Falk, J. (2011). Visitors' learning for environmental sustainability: testing short- and long-term impacts of wildlife tourism experiences using structural equation modelling. Tourism Manag. 32, 1243-1252. doi: 10.1016/j.tourman.2010.11.003 the conservation of the archipelagos in Costa Rica, Panama, Colombia, and Ecuador. One of the main goals of the initiative is to enhance protection of key migratory and endangered marine species, including hammerhead sharks and sea turtles. Increasing tourism opportunities in these islands will likely increase the number of visitors who can and are willing to donate toward the recovery of these two "umbrella" marine endangered species. Potential revenue from tourism can therefore be a feasible avenue through which funding for the CMAR initiative can occur.

\section{AUTHOR CONTRIBUTIONS}

SC and DL conceived and designed the study, and wrote the paper. SC carried out fieldwork and data analysis under DL's supervision.

\section{ACKNOWLEDGMENTS}

The authors are grateful to the Packard Foundation, the Latin American and Caribbean Environmental Economics Program (LACEEP), and the Mohammed Bin Zayed Fund for Endangered Species conservation for financial support provided; the GNP Service for granting the research permit required for the project; and the Charles Darwin Foundation for logistic support. A special thanks to all the volunteers who assisted with data collection and data entering. Thanks also to Jim Sanchirico, Mark Schwartz, Brian Garber-Yonts, Kristy Wallmo, and two reviewers for helpful comments. All remaining errors are the authors.' This article and its findings are those of the authors and do not necessarily reflect the views of the National Marine Fisheries Service or the U.S. Department of Commerce.

\section{SUPPLEMENTARY MATERIAL}

The Supplementary Material for this article can be found online at: http://journal.frontiersin.org/article/10.3389/fmars. 2016.00060

Balmford, A., Bennun, L., ten Brink, B., Cooper, D., Côte, I. M., and Crane, P. (2005). The convention on biodiversity's 2010 target. Science 307, 212-213. doi: 10.1126/science.1106281

Balmford, A., Gravestock, P., Hockley, N., McClean, C. J., and Roberts, C. M. (2003). The worldwide costs of marine protected areas. Proc. Natl. Acad. Sci. U.S.A. 101, 9694-9697. doi: 10.1073/pnas.0403239101

Baum, J., Clarke, S., Domingo, A., Ducrocq, M., Lamónaca, A. F., Gaibor, N., et al. (2007). Sphyrna lewini (Eastern Central and Southeast Pacific subpopulation). IUCN 2011. IUCN Red List of Threatened Species. Version 2011.2. Available online at: www.iucnredlist.org

Boxall, P. C., Adamowicz, W. L., Olar, M., West, G. E., and Cantin, G. (2012) Analysis of the economic benefits associated with the recovery of threatened marine mammal species in the Canadian St. Lawrence Estuary. Mar. Policy 36, 189-197. doi: 10.1016/j.marpol.2011.05.003

Choi, A. S., and Fielding, K. S. (2013). Environmental attitudes as WTP predictors: a case study involving endangered species. Ecol. Econ. 89, 24-32. doi: 10.1016/j.ecolecon.2013.01.027

Davis, D., Banks, S., Birtles, A., Valentine, P., and Cuthill, M. (2000). "Whale sharks in Ningaloo Marine Park: Managing tourism in an Australian marine protected 
area," in Tourism Management: Towards the New Millennium, eds C. Ryan and S. Page (Oxford: Pergamon), 281-299.

DeCaro, D., and Stokes, M. (2008). Social-psychological principles of communitybased conservation and conservancy motivation: attaining goals within an autonomy-supportive environment. Conserv. Biol. 22, 1443-1451. doi: 10.1111/j.1523-1739.2008.00996.x

Dikou, A. (2011). "Ecotourism in marine protected areas: development, impacts and management - a critical review," in Ecotourism: Management, Development and Impact. 1-42. Available online at: http://ir.lib.uth.gr/handle/11615/27046

Dunlap, R. E., and Jones, R. E. (2002). "Environmental concern: conceptual and measurement issues," in Handbook of Environmental Sociology, eds R. E. Dunlap and W. Michelson (Westport, CT: Greenwood Press), 482-524.

Dunlap, R. E., VanLiere, K. D., Mertig, A. G., and Jones, R. E. (2000). Measuring endorsement of the new ecological paradigm: A revised NEP scale. J. Soc. Issues 56, 425-442. doi: 10.1111/0022-4537.00176

Fulton, D. C., Manfredo, M. J., and Lipscomb, J. (1996). Wildlife value orientations: a conceptual and measurement approach. Hum. Dimens. Wildl. 1, 24-47. doi: $10.1080 / 10871209609359060$

Gell, F. R., and Roberts, C. M. (2003). Benefits beyond boundaries: the fishery effects of marine reserves. Trends Ecol. Evol. 18, 448-455. doi: 10.1016/S01695347(03)00189-7

Gladstone, W., Curley, B., and Shokri, M. R. (2013). Environmental impacts of tourism in the Gulf and the Red Sea. Mar. Pollut. Bull. 72, 375-388. doi: 10.1016/j.marpolbul.2012.09.017

Gravestock, P., Roberts, C. M., and Bailey, A. (2008). The income requirements of marine protected areas. Ocean Coast. Manag. 51, 272-283. doi: 10.1016/j.ocecoaman.2007.09.004

Greene, W. H. (2011). Econometric Analysis, 7th Edn. Upper Saddle River, NJ: Pearson/Prentice Hall.

Hall, C. M. (2001). Trends in ocean and coastal tourism: the end of the last frontier? Ocean Coast. Manag. 44, 601-618. doi: 10.1016/S0964-5691(01)00071-0

Halpenny, E. A. (2003). "NGOs as conservation agents: achieving conservation through marine ecotourism," in Marine Ecotourism: Issues and Experiences, eds B. Garrod and J. C. Wilson (London: Channel View Publications), 107-121.

Ham, S. H., and Weiler, B. (2012). "Interpretation as the centerpiece of sustainable wildlife tourism," in Sustainable Tourism, eds R. Harris, T. Griffin, and P. Williams (Oxford: Butterworth-Heinemann), 35-44.

Hoyt, E. (2001). Whale Watching 2001: Worldwide Tourism Numbers, Expenditures, and Expanding Socioeconomic Benefits. Crowborough: International Fund for Animal Welfare (IFAW).

IUCN (2008). Towards Networks of Marine Protected Areas - The MPA Plan of Action for IUCN's World Commission on Protected Areas. IUCN.

Jacobson, S., Sieving, K., Jones, G., and Van Doorn, A. (2003). Assessment of farmer attitudes and behavioral intentions toward bird conservation on organic and conventional florida farms. Conserv. Biol. 17, 595-606. doi: 10.1046/j.15231739.2003.01472.x

Kamrowski, R., Sutton, S., Tobin, R., and Hamann, M. (2014). Potential applicability of persuasive communication to light-glow reduction efforts: a case study of marine turtle conservation. Environ. Manage. 54, 583-595. doi: 10.1007/s00267-014-0308-9

Kerstetter, D. L., Hou, J., and Lin, C. (2004). Profiling Taiwanese ecotourists using a behavioral approach. Tourism Manag. 25, 491-498. doi: 10.1016/S02615177(03)00119-5

Kil, N., Holland, S. M., and Stein, T. V. (2014). Structural relationships between environmental attitudes, recreation motivations, and environmentally responsible behaviors. J. Outdoor Recreation Tourism 7-8, 16-25. doi: 10.1016/j.jort.2014.09.010

Kotchen, M. J., and Reiling, S. D. (2000). Environmental attitudes, motivations, and contingent valuation of non-use values: A case study involving endangered species. Ecol. Econ. 32, 93-107. doi: 10.1016/S0921-8009(99) 00069-5

Lew, D. K. (2015). Willingness to pay for threatened and endangered marine species: a review of the literature and prospects for policy use. Front. Mar. Sci. 2:96. doi: 10.3389/fmars.2015.00096

Lew, D. K., Layton, D. F., and Rowe, R. D. (2010). Valuing enhancements to endangered species protection under alternative baseline futures: the case of the steller sea lion. Mar. Resour. Econ. 25, 133-154. doi: 10.5950/0738-136025.2.133
Lynne, G. D., and Rola, L. (1988). Improving attitude-behavior prediction models with economic variables: farmer actions toward soil conservation. J. Soc. Psychol. 128, 19-28. doi: 10.1080/00224545.1988.9711680

Maddala, G. S. (1983). Limited Dependent and Qualitative Variables in Econometrics. Cambridge: Cambridge University Press.

Marine Conservation Institute (2015). MPAtlas.

Masters, D. (1998). Marine Wildlife Tourism: Developing a Quality Approach in the Highlands and Islands. A report for the Tourism and Environment Initiative and Scottish Natural Heritage. Sustainable Tourism Unit. Available online at: http://www.greentourism.org.uk/publications.html (Accessed March 19, 2008).

Mayes, G., Dyer, P., and Richins, H. (2004). Dolphin-human interaction: proenvironmental attitudes, beliefs and intended behaviours and actions of participants in interpretation programs: a pilot study. Ann. Leis. Res. 7, 34-53. doi: 10.1080/11745398.2004.10600938

McFadden, D. (1974). "Conditional logit analysis of qualitative choice behavior," in Frontiers in Econometrics, ed P. Zarembka (New York, NY: Academic Press), 105-142.

Metrick, A., and Weitzman, M. L. (1996). Patterns of behavior in endangered species preservation. Land Econ. 72, 1-16. doi: 10.2307/3147153

Milfont, T. L., and Duckitt, J. (2010). The environmental attitudes inventory: A valid and reliable measure to assess the structure of environmental attitudes. J. Environ. Psychol. 30, 80-94. doi: 10.1016/j.jenvp.2009.09.001

Observatorio de Turismo de Galapagos (OTG) (2015). Boletin Galapagos 2015. Puerto Ayora: Ministerio de Turismo del Ecuador y Parque Nacional Galapagos.

Orams, M. B. (2003). "Marine ecotourism in New Zealand: an overview of the industry and its management," in Marine Ecotourism: Issues and Experiences, eds B. Garrod and J. C. Wilson (Clevedon: Channel View), 233-248.

Perry-Hill, R., Smith, J., Reimer, A., Mase, A., Mullendore, N., Mulvaney, K., et al. (2014). The influence of basic beliefs and object-specific attitudes on behavioural intentions towards a rare and little-known amphibian. Wildl. Res. 41, 287-299. doi: 10.1071/WR13218

Peters, H., and Hawkins, J. P. (2009). Access to marine parks: a comparative study in willingness to pay. Ocean Coast. Manag. 52, 219-228. doi: 10.1016/j.ocecoaman.2008.12.001

Polidoro, B. A., Brooks, T. K., Carpenter, E., Edgar, G. J., Henderson, S., Sanciangco, J., et al. (2012). Patterns of extinction risk and threat for marine vertebrates and habitat species in the Tropical Eastern Pacific. Mar. Ecol. Prog. Ser. 448, 93-104. doi: 10.3354/meps09545

Richardson, L., and Loomis, J. (2009). The total economic value of threatened, endangered and rare species: an updated meta-analysis. Ecol. Econ. 68, 15351548. doi: 10.1016/j.ecolecon.2008.10.016

Roberge, J.-M., and Angelstam, P. (2004). Usefulness of the umbrella species concept as a conservation tool. Conserv. Biol. 18, 76-85. doi: 10.1111/j.15231739.2004.00450.x

Rodrigues, A. S. L., Andelman, S. J., Bakarr, M. I., Boitani, L., Brooks, T. M., Cowling, R. M., et al. (2004). Effectiveness of the global protected area network in representing species diversity. Nature 428, 640-643. doi: 10.1038 /nature02422

Schwartz, S. H. (1977). Normative influences on altruism. Adv. Exp. Soc. Psychol. 10, 221-279. doi: 10.1016/S0065-2601(08)60358-5

Seminoff, J. (2004). Marine Turtle Specialist Group Chelonia mydas Assessment. IUCN Marine Turtle Specialist Group.

Snell, H. M., Stone, P. A., and Snell, H. L. (1996). Special Paper: A Summary of geographical characteristics of the galapagos Islands. J. Biogeogr. 23, 619-624. doi: 10.1111/j.1365-2699.1996.tb00022.x

Spash, C. L., Urama, K., Burton, R., Kenyon, W., Shannon, P., and Hill, G. (2009). Motives behind willingness to pay for improving biodiversity in a water ecosystem: Economics, ethics and social psychology. Ecol. Econ. 68, 955-964. doi: 10.1016/j.ecolecon.2006.09.013

Stern, P. C. (2000). Toward a coherent theory of environmentally significant behavior. J. Soc. Issues 56, 407-424. doi: 10.1111/0022-4537.00175

Stern, P. C., Dietz, T., Abel, T., Guagnano, G. A., and Kalof, L. (1999). A value-belief-norm theory of support for social movements: the case of environmentalism. Res. Hum. Ecol. 6, 81-97.

Stoeckl, N., Birtles, A., Farr, M., Mangott, A., Curnock, M., and Valentine, P. (2010). Live-aboard dive boats in the Great Barrier Reef: regional economic 
impact and the relative values of their target marine species. Tourism Econ. 6, 995-1018. doi: 10.5367/te.2010.0005

Stoeckl, N., Smith, A., Newsome, D., and Lee, D. (2005). Regional economic dependence on iconic wildlife tourism: case studies of Monkey Mia and Hervey Bay. J. Tourism Stud. 16, 69-81.

Thapa, B. (2010). The mediation effect of outdoor recreation participation on environmental attitude-behavior correspondence. J. Environ. Educ. 41, 133-150. doi: 10.1080/00958960903439989

Tisdell, C., and Wilson, C. (2001). Wildlife-based tourism and increased support for nature conservation financially and otherwise: evidence from sea turtle ecotourism at mon repos. Tourism Econ. 7, 233-249. doi: $10.5367 / 000000001101297847$

Wallmo, K., and Lew, D. K. (2012). Public values for recovering and downlisting threatened and endangered marine species. Conserv. Biol. 26, 830-839. doi: 10.1111/j.1523-1739.2012.01899.x

Wallmo, K., and Lew, D. K. (2015). Public preferences for endangered species recovery: an examination of geospatial scale and non-market values. Front. Mar. Sci. 2:55. doi: 10.3389/fmars.2015.00055

Wilson, C., and Tisdell, C. (2001). Sea turtles as a non-consumptive tourism resource especially in Australia. Tourism Manag. 22, 279-288. doi: 10.1016/S0261-5177(00)00059-5
Yazdanpanah, M., Hayati, D., Hochrainer-Stigler, S., and Zamani, G. H. (2014). Understanding farmers' intention and behavior regarding water conservation in the Middle-East and North Africa: A case study in Iran. J. Environ. Manage. 135, 63-72. doi: 10.1016/j.jenvman.2014. 01.016

Zeppel, H. (2008). Education and conservation benefits of marine wildlife tours: developing free-choice learning experiences. J. Environ. Educ. 39, 3-18. doi: 10.3200/JOEE.39.3.3-18

Zeppel, H., and Muloin, S. (2008). Tourism in marine environments. 5, 215-227. doi: $10.3727 / 154427308787716802$

Conflict of Interest Statement: The authors declare that the research was conducted in the absence of any commercial or financial relationships that could be construed as a potential conflict of interest.

Copyright () 2016 Cárdenas and Lew. This is an open-access article distributed under the terms of the Creative Commons Attribution License (CC BY). The use, distribution or reproduction in other forums is permitted, provided the original author(s) or licensor are credited and that the original publication in this journal is cited, in accordance with accepted academic practice. No use, distribution or reproduction is permitted which does not comply with these terms. 